\title{
Water birth, more than a trendy alternative: a prospective, observational study
}

\author{
Rosanna Zanetti-Dällenbach • Olav Lapaire • \\ Anne Maertens · Wolfgang Holzgreve · Irene Hösli
}

Received: 12 May 2006 / Accepted: 30 June 2006 / Published online: 26 July 2006

(C) Springer-Verlag 2006

\begin{abstract}
Objective To prospectively assess the effect of water birth on maternal and fetal outcomes in a selected lowrisk collective of a tertiary obstetrical unit.

Method In this prospective observational study, 513 patients of a low-risk collective, who requested a water birth, were studied during the years 1998-2002. Primary outcome measurements included the maternal and fetal parameters. Secondary outcome measurements comprised data on the incidence of water births in an interested, low-risk population in an academic hospital.

Result All groups were similar in terms of demographic and obstetric data. Significant differences were observed in maternal outcome parameters, which included the use of analgesia/anesthesia during labor, the duration of first and second stages of labor, perineal tears and episiotomy rate. No differences were seen in all observed fetal outcome parameters including APGAR scores, arterial and venous $\mathrm{pH}$, admission rate to neonatal intensive care unit and infection rate. Conclusion Water birth is a valuable and promising alternative to traditional delivery methods. The maternal and fetal outcomes were similar to traditional land births. However, currently there still exist some deficits in the scientific evaluation of its safety. Therefore, the
\end{abstract}

\footnotetext{
R. Zanetti-Dällenbach · O. Lapaire · A. Maertens ·

W. Holzgreve · I. Hösli

The Women's University Hospital,

University Hospital Basel, Basel, Switzerland

R. Zanetti-Dällenbach $(\bowtie)$

Universitäts-Frauenklinik Basel, Basel,

4031 Basel, Switzerland

e-mail: rzanetti@uhbs.ch
}

selection of a low-risk collective is essential to minimize the risks with the addition of strictly maintained guidelines and continuous intrapartum observation and fetal monitoring. Based on our results and the literature, water births are justifiable when certain criteria are met and risk factors are excluded.

Keywords Water birth $\cdot$ Immersion $\cdot$ Delivery

\section{Introduction}

The first single report of a successful water birth in a medical journal is dated 1805, when a French woman gave birth to a healthy infant in a bathtub [1]. In 1983, Odent [2] published the results of more than 100 water births. More than 20 years later, bathing for pain relief during labor or for delivery itself has gained much popularity, especially in western countries, like England, Germany, Switzerland or Austria. As a consequence, the House of Commons Health Committee [3] in the United Kingdom released a statement in 1992 that "all women should be offered the option of a birthing pool during labour and birth". Therefore it is not surprising that the rate of obstetrical providers who offer this method is rising. A recent survey among all Germanspeaking obstetrical units $(n=1,277)$ with a rate of return of $78 \%(n=881)$ showed that $25 \%$ offered water births. Of those, $22 \%(n=218)$ who did not provide water births in 1997 introduced this innovative delivery method in 1998 [4]. Although the Royal College of Obstetricians and Gynecologists already published guidelines stating that there appears to be no difference in the outcome, there is still an ongoing debate about the safety, general outcome and impact 
of water births [5]. The literature referring to water births provides some evidence that the overall outcome is similar or even better than that achieved with traditional methods. The outcome parameters of water births have been studied only in a few prospective observational studies, prospective pilot studies, retrospective studies and empirical reports, which were biased by individual or institutional experiences [6-9]. Therefore this study sought to investigate, in a prospective manner in a tertiary obstetrical unit and in a pre-selected low-risk collective, both maternal and fetal outcomes and identify factors predictive for water births.

\section{Materials and methods}

The institutional review board of Basel University Women's Hospital, Switzerland, approved this prospective observational study, and written informed consent was obtained from all participating patients. Between April 1998 and May 2002, a total of 521 patients consented to participate after being assessed for eligibility (Fig. 1). Eight of them were excluded from further participation in the course of the study, either for medical or demographic reasons. During the routine medical checkups in our antenatal clinic, all pregnant women at low risk for obstetrical and/or maternal complications were informed in the late second and third trimesters about the availability of water deliveries. Every interested woman was given detailed explanations and information about the inclusion and exclusion criteria and about our guidelines concerning the safety of water birth, either by a trained resident, fellow or midwife. Inclusion criteria were delivery at our tertiary obstetric care center, single pregnancy with cephalic presentation at term ( $>37$ weeks of gestation), current negative results on HIV, Hepatitis B and $\mathrm{C}$, continuous fetal cardiotocogram (CTG) and observation of the patient, venous access during labor and leaving the bath in case of a suspicious or pathological CTG, according to the RCOG guidelines [10]. Exclusion criteria consisted of intrauterine growth restriction $(<5$ th percentile), meconium-stained amniotic fluid, pathological and suspicious CTG, maternal infection with HIV, Hepatitis B, Hepatitis C or acute Herpes genitalis, fetal macrosomia ( $>$ 95th percentile), history of shoulder dystocia, epidural anesthesia and intravenous sedation. All patients agreed to be tested for HIV, Hepatitis B and C before admission to protect the staff from infections, according to the requirements of the institutional review board. If a woman tested positive or the results were not available until delivery, a water birth could not be performed. All members of the obstetrical unit underwent a vaccination for Hepatitis B prior to conducting water births and were obligated to wear gloves during labor and delivery. All patients willing to participate were also screened for Group B streptococcus (GBS) in the 37th week of gestation. GBS-positive women received chemoprophylaxis with $2.2 \mathrm{~g}$ ampicillin and clavulanic acid intravenously during labor. After admission to the maternity room, enemas were offered. The woman could enter the bathtub whenever she desired preferentially at a cervical dilatation of approximately $5 \mathrm{~cm}$. The water temperature varied between 32 and $36^{\circ} \mathrm{C}$. We did not recommend bath products (such as soaps or foam bath additives) because these could obscure the color of the water. The fetal heart rate was monitored continuously (cardiotocogram by telemetry; Hewlett Packard 71034 Boehringer, Germany). The subsequent management of labor was identical for all groups. In case of failure of cervical dilatation $(<1 \mathrm{~cm} / \mathrm{h})$, intravenous oxytocin by infusion pump was initiated with increasing doses from 1.25 up to $20 \mathrm{mU} / \mathrm{min}$, and/or rupture of the membranes was initiated. A patient's desire for alternative forms of pain relief was fully respected. Standard intravenous analgesics and homeopathies were used as first line drugs upon request of the woman. Yet if an epidural blockade was required, further submersion in water was not possible. In case of water birth, the midwife ensured a controlled delivery of the head, and the baby was brought gently but within seconds to the surface and placed on the mother's chest. The midwife clamped and subsequently cut the umbilical cord. After the delivery, 5 IU oxytocin was applied intravenously. If the placenta was not delivered within $10 \mathrm{~min}$ postpartum, or if there was an increased blood loss, the patient had to leave the bathtub. After having drained the water, the bathtub was cleaned first with soap and water and subsequently with Kohrsolin FF Concentrate (Bode Chemie, Hamburg, Germany), containing glutaraldehyde, benzalkoniumchloride and didecyldimethylammoniumchloride, according to the infection control policy and allowed to air-dry between each use.

To reduce the risk of an infection with Pseudomonas the water tap was fully opened for several minutes, before filling the tub. All data were prospectively collected by midwifes or residents and documented on the trial entry form in the patients' hospital records. After the study's completion, the clinical data were filled in an excel sheet by a member of the research team. This research team member was not responsible for providing patient care. The primary outcome measure was the maternal outcomes of use of analgesia/anesthesia 


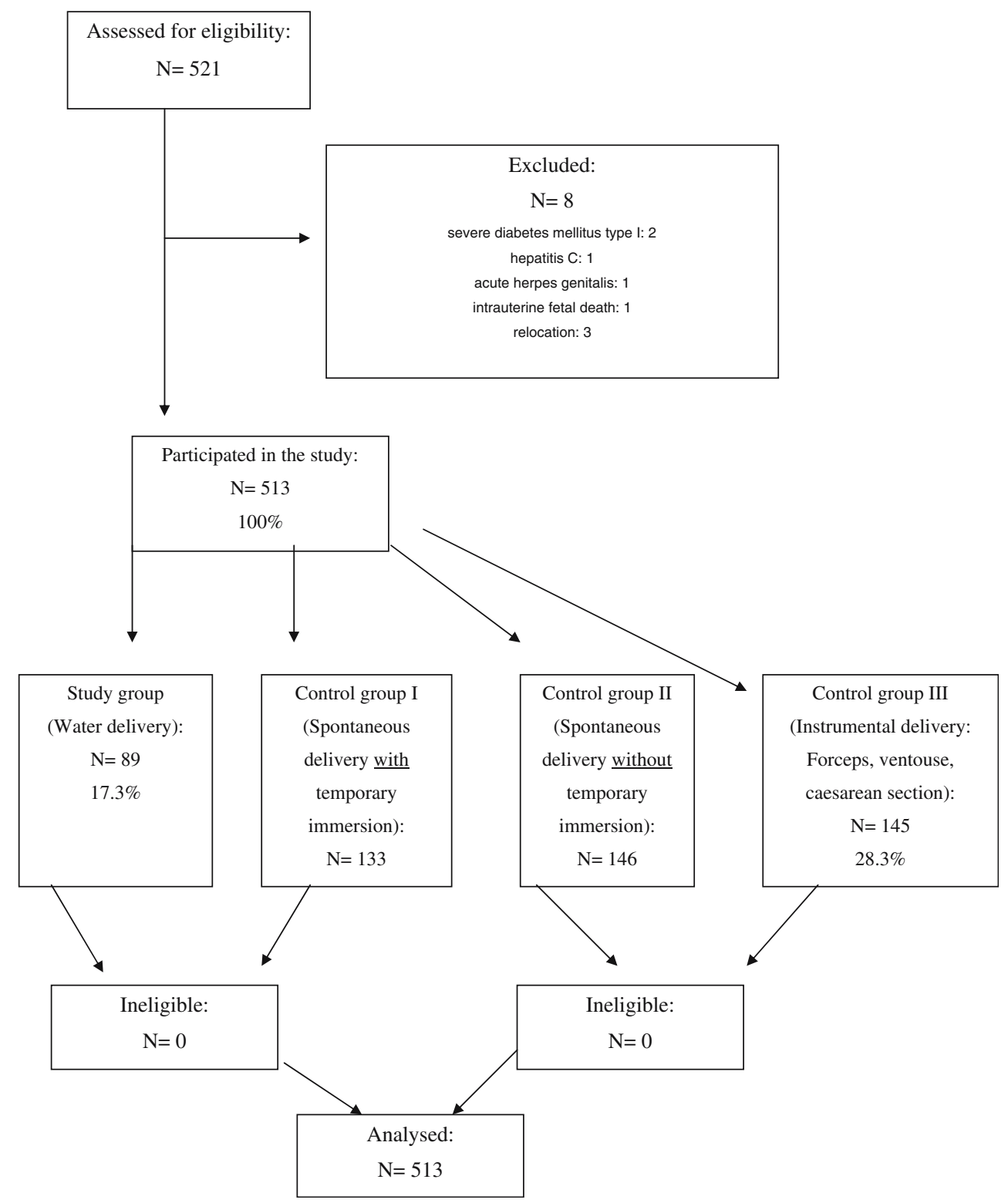

Fig. 1 Flow chart of participants through the prospective study

during labor, duration of labor and birth, blood loss during birth, injuries of the birth canal and maternal infection. The fetal outcomes included APGAR score at 1 and $5 \mathrm{~min}$, cord $\mathrm{pH}$ immediately after birth, admittance to neonatal care unit and signs of postpartum infections. As a secondary outcome measurement we collected data on the incidence of water births in an interested, low-risk population in our tertiary teaching hospital.

Student's $t$ test and Welch test (if variances in groups are unequal) were used to compare approximate normally distributed data in the groups. MannWhitney $U$ test was used for the ordinal data. As a measure of correlation, Spearman rank order correlation was calculated. All variables used were described by mean, median, standard deviation (SD) and minimal and maximal values.

If variables were categorical, cross tabs were formed and Fisher's exact test was applied, calculating the relative risk with corresponding $95 \%$ confidence intervals. To compare several subgroups with continuous data, one-way ANOVAs were performed. Because of the purely exploratory character of the study the $P$ values were not adjusted for a specific variable due to multiple comparisons.

A $P$ value $<0.05$ was considered significant. All analyses were performed using SPSS (SPSS, Inc., Chicago, USA) 11.5.1. 


\section{Results}

On initial screening in our antenatal clinic, 521 patients were interested in having a water birth (see Fig. 1). All of them signed the informed consent. The collective represented $7.7 \%$ of all deliveries $(n=6,800)$ at the Basel University Women's Hospital between April 1998 and May 2002. Eight of the 521 patients were excluded from participation, either due to medical reasons (two patients with severe diabetes mellitus type I) or exclusion criteria: one woman had hepatitis $\mathrm{C}$, one suffered from acute herpes genitalis and one patient mourned an intrauterine fetal death. Furthermore, three women moved before birth and therefore could not deliver in our institution. All the remaining 513 women met the inclusion criteria. According to the course of delivery, four different groups were designated: 89 pregnant women $(17.4 \%)$ delivered in water and constituted the study group (SG), 133 patients $(25.9 \%)$ had a normal vaginal delivery after temporary immersion and formed the control group I (CG I), whereas 146 women $(28.5 \%)$ had a normal vaginal delivery but no temporary immersion and established therefore control group II (CG II). Control group III (CG III) consisted of 145 patients $(28.3 \%)$ who had an operative delivery, either by cesarean section (49 [9.5\%]) or by vaginal assisted delivery (96 [18.7\%]) with forceps or vacuum.

The study group and its control groups were comparable in terms of demographic and obstetric data, such as maternal age, gestational age, birth weight, maternal occupation and medical insurance, a parameter with a good correlation to the socioeconomic background (see Table 1). Only gravidity and parity were significantly different. CG I and III comprised significantly less multiparae than the SG and CG II. A similar trend was seen in the number of previous pregnancies. Furthermore, the ethnical background of the collective was recorded according to their origin: local Swiss population, Mediterranean origin (Portugal, Spain, Italy, ex-Yugoslavian, Turkey) and others. Swiss patients were found significantly less often in the control group II, compared to SG (59.6 vs $77.5 \%$ ), $P$ : 0.011 . In contrast, more patients with a Mediterranean origin were found in the CG II. Furthermore, CG I and III featured significantly more often preterm rupture of membranes compared to the SG.

The need for additional analgesics was significantly higher in two control groups (CG I and CG III) compared to the study group, $P<0.001$ (see Table 2). The request for homeopathy as analgesic therapy was also higher in all control groups, reaching non-significance in level in CG II. Epidural anesthesia was not allowed in the case of a water birth. The prevalence of epidural anesthesia was $50 \%$ in CG I, 38\% in CG II and $94 \%$ in CG III. The mean values for the duration of first stage of labor were significantly longer in the two control groups (CG I, $P: 0.003$ and CG III, $P<0.001$ ), compared to the water delivery group, maybe biased by parity (see Table 2). There were no differences in prolonged first stage of labor between the SG and control groups, except in CG III $(P<0.001)$. In contrast, prolonged second stage of labor was significantly longer in all control groups $(P: 0.02)$.

The CTG during the first stage of labor was significantly more often pathological in the CG I ( $P: 0.02)$ and CG III $(P<0.001)$ than in the SG (see Table 2$)$. Significantly more pathological CTGs were recorded in all control groups in the second stage of labor $(P<0.001)$. Intravenous oxytocin and uterine relaxants were significantly more often used in all control groups $(P<0.001)$. In the instrumental delivery group there was a higher incidence of meconium-stained fluid, although this did not reach statistical significance $(P$ : 0.052) compared to SG.

Significantly more episiotomies were cut in all control groups, compared to the study group $(P<0.001$, see Table 3$)$. In contrast, more first and second-degree perineal lacerations occurred in the water delivery group. We observed no third-degree perineal lacerations in the study group. Its incidence was $2.3 \%$ in CG I and $0.7 \%$ in CG II (see Table 3). No shoulder dystocia occurred in any group.

In the study group, $57 \%$ of patients delivered the placenta in the tub. The third stage of labor lasted significantly longer in the water delivery group, compared to the control groups $(P<0.001)$. This result had no influence on the estimated blood loss or in the postpartum hemoglobin levels: maternal blood loss was significantly higher in control group III compared to the study group (see Table 5). A retained placenta was a rare event in all groups (see Table 3 ).

The mean birth weight was similar in all groups. Significantly lower APGAR scores at 1 min were seen in the control group III $(P<0.001)$, with no statistically significant difference with the other groups after $5 \mathrm{~min}$. A statistically significant lower arterial $\mathrm{pH}$ value was seen in CG III, $P: 0.02$. Significantly lower venous $\mathrm{pH}$ measurements were observed in all control groups compared to the water delivery group, $P<0.05$. All four groups were comparable regarding the rate of admission to the NICU (see Table 4).

No significant differences occurred among the groups in the hemoglobin or hematocrit values assessed in the third trimester and in the first stage of labor (see Table 5). Hemoglobin and hematocrit values 


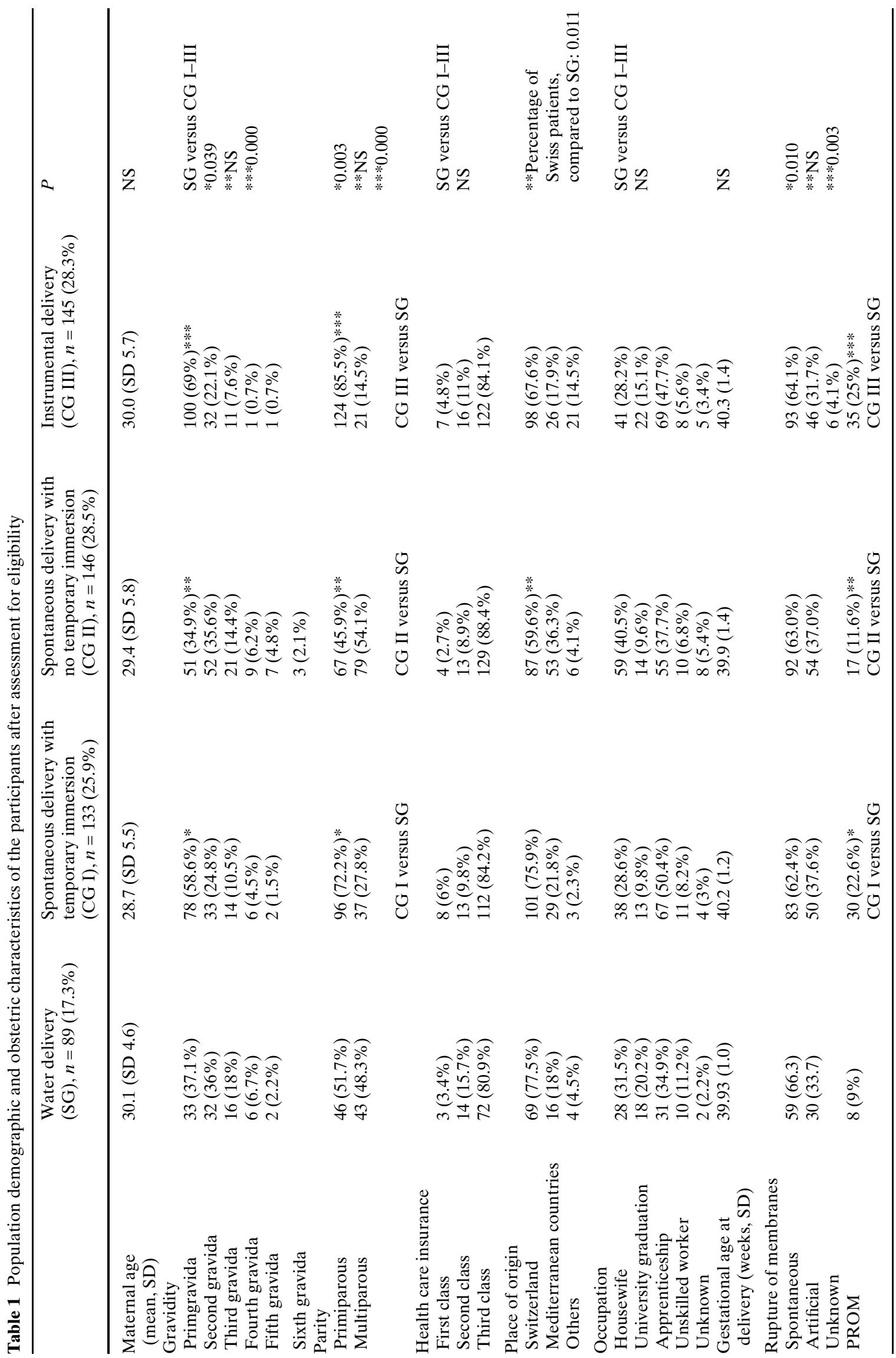




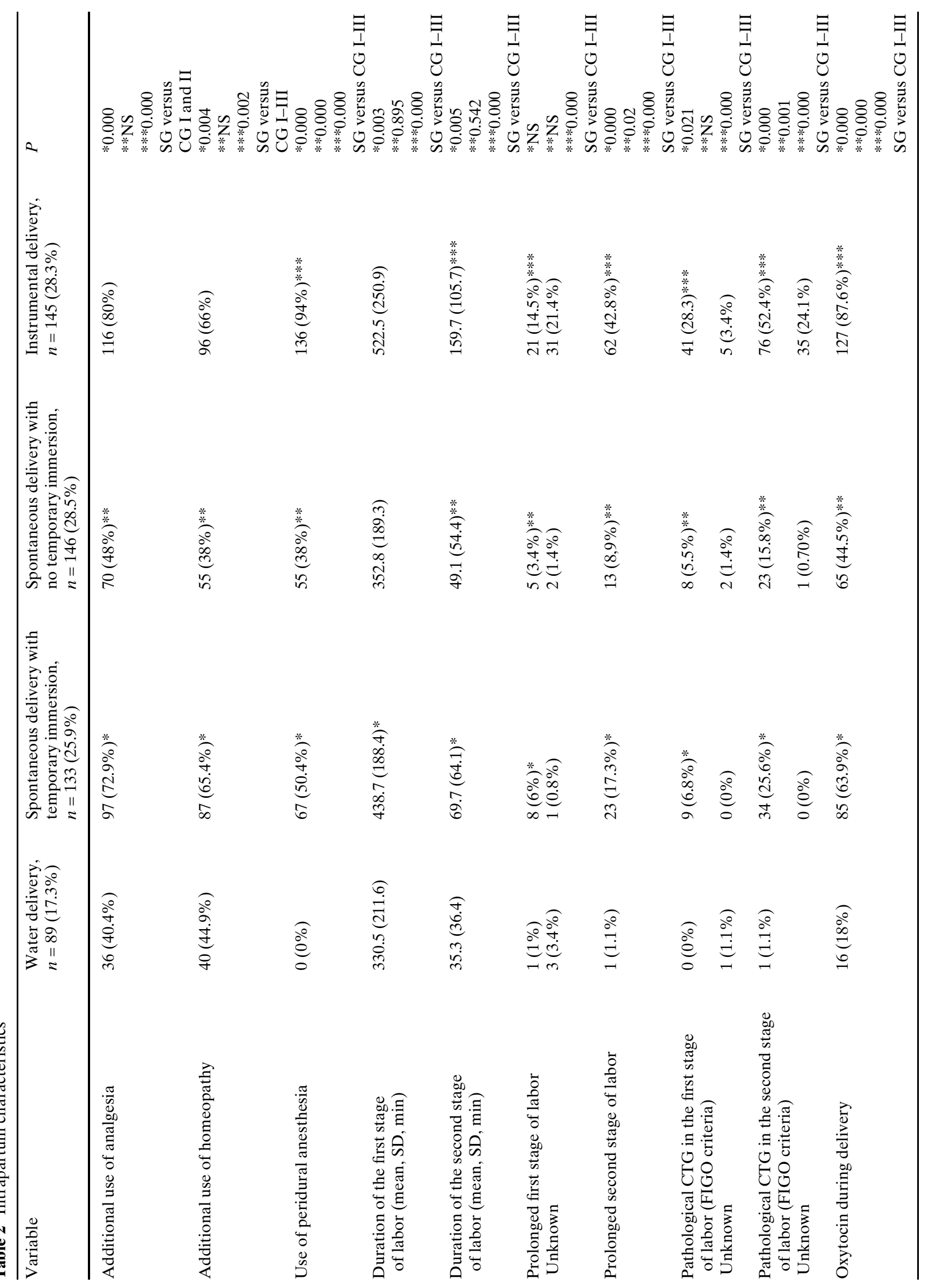


were significantly lower in all control groups (except hematocrit in CG II) assessed 2 days postpartum, $P<0.05$ (see Table 5). The maternal temperature measured on admission and 2 days postpartum did not show any differences in all groups. We did not observe any clinical signs of postpartum infections, which could have been related to the water deliveries.

\section{Discussion}

Water births have become very popular in recent years, especially in German-speaking countries. Advocates of this form of delivery emphasize the advantages, mainly painless births, gentler experience for the newborn, less severe injuries to the birth canal and increased maternal autonomy, although most of these claims have not been scientifically proven $[11,12]$. On the other hand, antagonists of water births argue that negative maternal side effects (e.g., increased blood loss, lack of perineal control and secondary perineal trauma, increased risk of infection) and fetal risks (aspiration, hypoxemia, infection, pulmonary edema, hyponatriemia) may occur [13-17], but some of these objections are not scientifically evaluated. On the basis of these conflicting reports and lack of sufficient data, discussion about the safety of water births is still ongoing. A recently published Cochrane review stated that no adverse neonatal outcomes after immersion in the first stage of labor have been observed [18]. Nevertheless, insufficient data have assessed the effect of immersion in water in the second and third stages of labor. Severe concerns, especially in the USA, have arisen about possible adverse events that may have been associated with water births [19]. The lack of evidencebased data has been objected by the antagonists of water births. We agree with this fair comment, yet adding that this drawback can only be resolved with additional, well-designed studies. In order to obtain some more data, we performed this observational study. Overall, only $1.3 \%$ of all deliveries in our tertiary perinatal center during the study period occurred in water. This small number is consistent with those of other tertiary centers, which showed similar percentages [2022]. A high percentage of multiparae underwent water delivery. We speculate that multiparous women generally experience a shorter duration of labor and possibly even less pathological CTG tracing secondary to this. A possible negative experience with a first land birth also may contribute to the multipara's decision to participate in an underwater birth. Many proponents of water births emphasize that water births are associated with less pain and fewer rates of epidural analgesia, as 


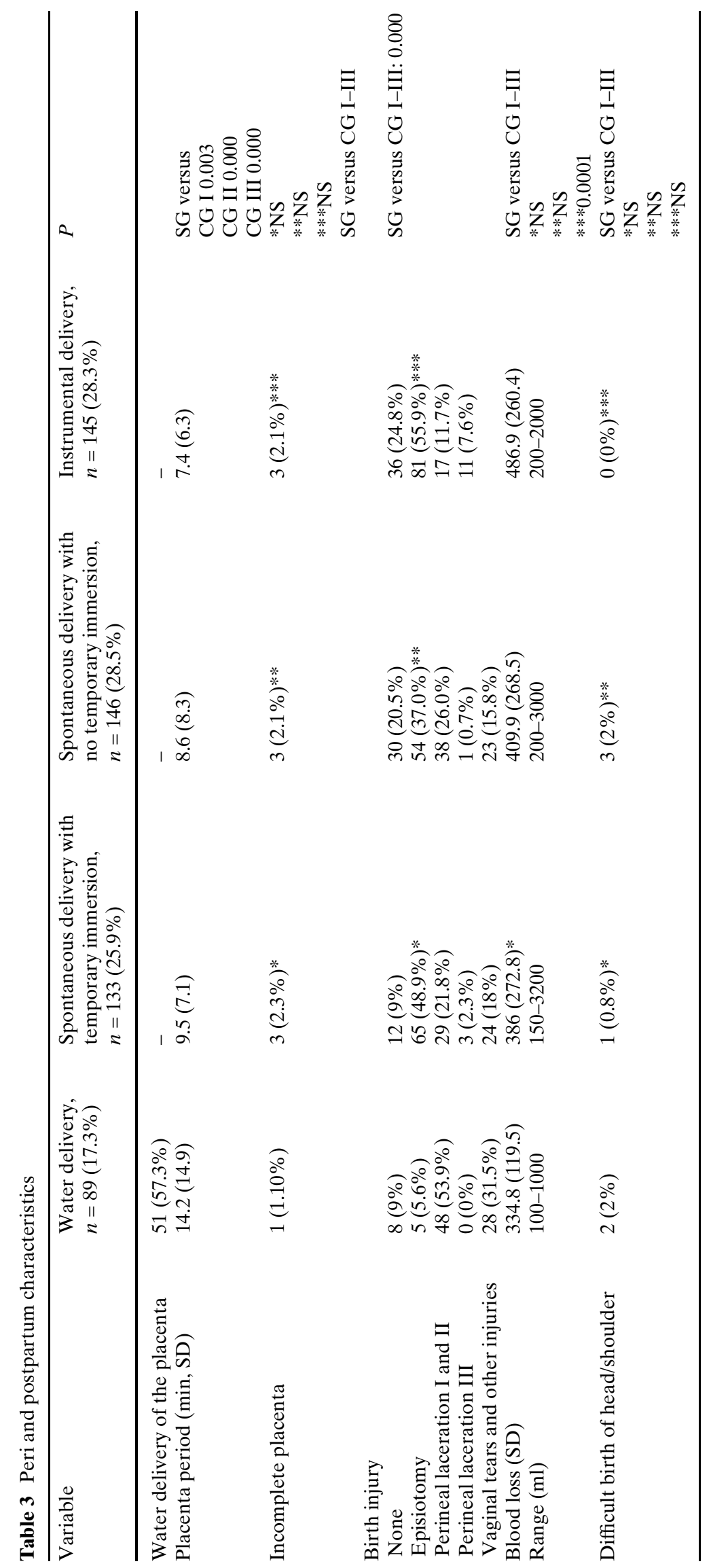




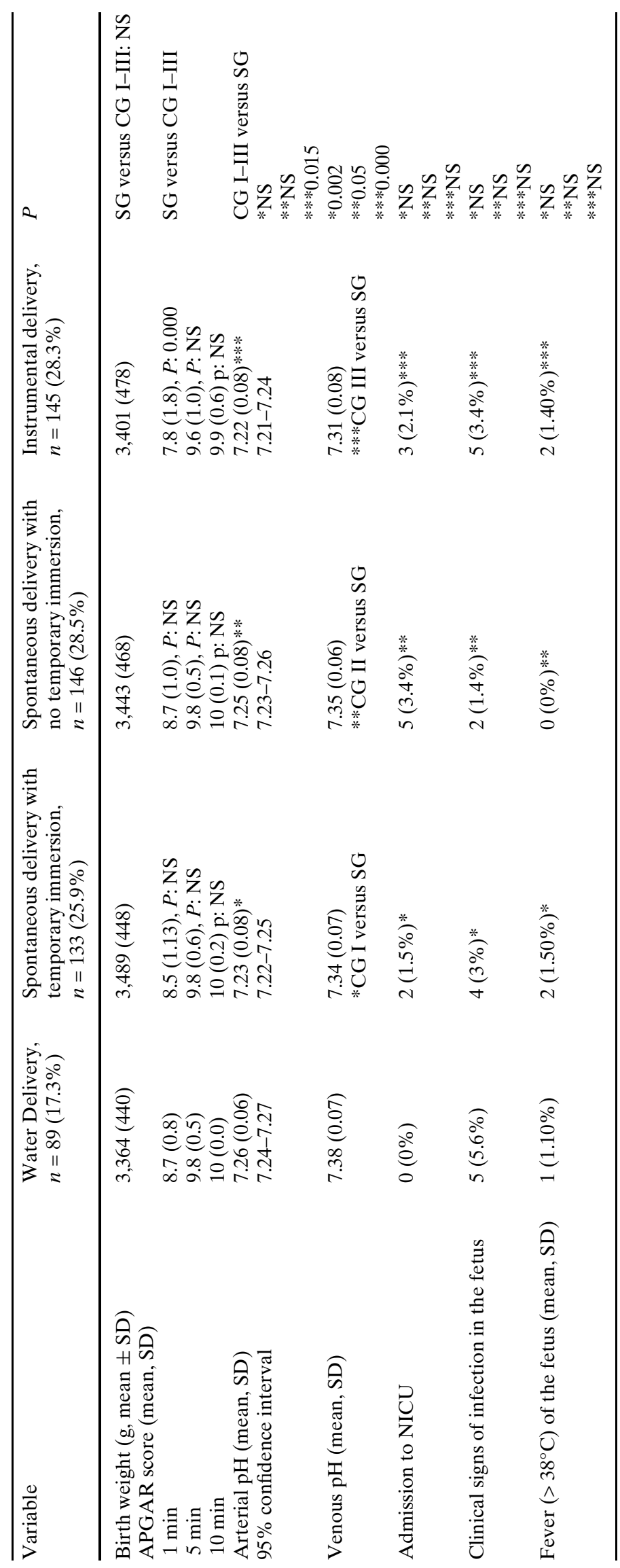




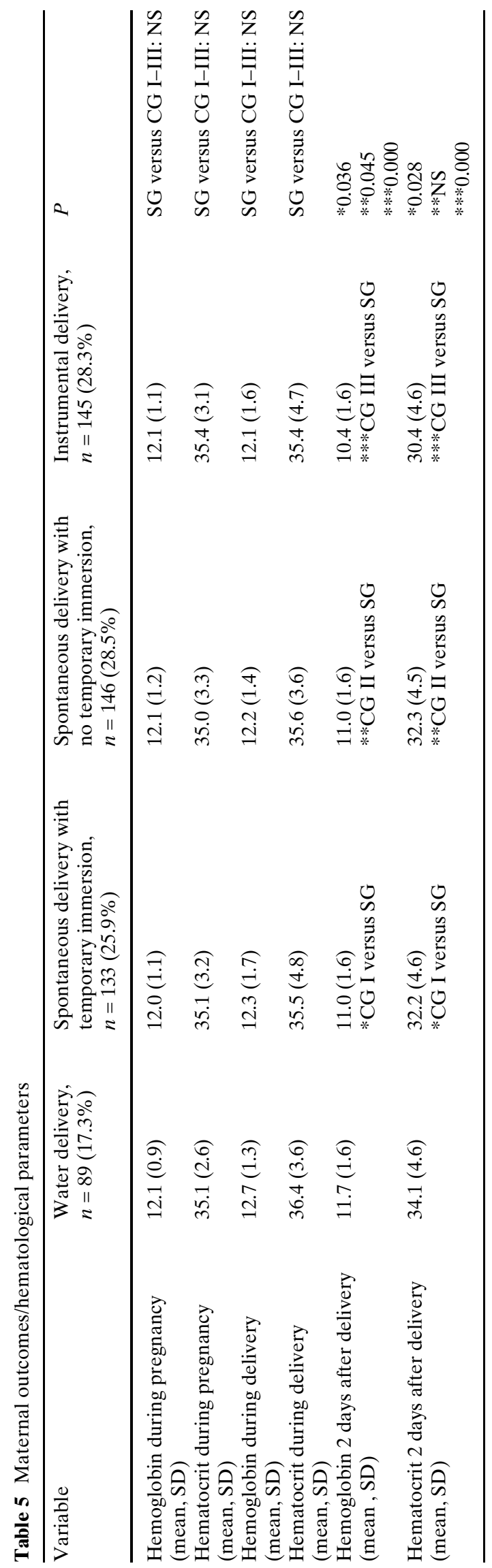

confirmed by several studies [23-25]. The data are consistent with those of our observational study where significantly less additional conventional analgesics, homeopathies and epidural analgesia were requested and utilized in the study group. Our study demonstrated a strong dependency on the rate of episiotomies and delivery mode, as well as the incidence of first and second-degree tears, a finding not reported by the Cochrane review [18]. This difference may be explained with a careful, comprehensive training of all involved occupation groups (midwifes, residents, fellows and affiliated). Unlike some data in the literature, we found a significantly longer first stage of labor in two of the control groups (CG I and III) [11, 24, 25, 26]. Data from a large observational study with over 3,600 water deliveries [7] support our findings, whereas other trials did not show statistically significant difference $[11,24,27]$. We speculate that the combination of maternal relaxation, improved uterine perfusion and permanent attendance of midwifes as well as parity contributed to the superior results in our water delivery group. A certain delay in the progression of delivery may also be reflected in the increased use of oxytocin in the control groups. The CTG during the first stage of labor was significantly more often considered to be pathological in the CG I and CG III than in the SG, whereas the CTG was significantly more often pathological in all three control groups during the second stage of labor. This may be biased by parity and the duration of first and second stages of labor.

Our study results are consistent with those of the Cochrane review [18] that there were no significant differences in the incidence of low APGAR scores, higher admission rates to NICUS or higher incidence of neonatal infections, similar to a recently published observational study [7]. In contrast to the study of Geissbuehler et al., where a minimal arterial $\mathrm{pH}$ of 6.88 (mean value 7.29, range 6.88-7.54) in the water delivery group was recorded, our study group showed no arterial $\mathrm{pH}$ of $\leq 7.13$. This may be explained with the pre-selection of the collective and the rigorous inclusion and exclusion criteria. Furthermore, none of the other negative fetal outcome parameters, mentioned by antagonists of water births such as aspiration, hypoxemia, pulmonary edema, consecutive hyponatriemia, was observed. Some authors reported similar results to our study and found no differences in fetal and maternal outcomes [2,28], but others have demonstrated the converse $[13,15,29,30]$.

In conclusion, our data indicate that water deliveries performed in a pre-selected low-risk collective motivated to undergo this delivery mode are safe and not associated with an adverse maternal or fetal outcome, 
as long as full attention of the safety policy is warranted. However, there is a lack in the scientific evaluation of the safety of this method. Therefore we do not recommend this way of delivery without a careful selection of the candidates. It is equally important to strictly adhere to guidelines and to use continuous intrapartum observation as well as fetal monitoring.

Acknowledgment The science fund of the University Hospital Basel, Switzerland, provided financial support. There are no conflicts of interest to declare.

\section{References}

1. Embry M (1805) Observations sur un accouchement termine dans le bain. Ann Soc Med Pract Montp 53:185-191

2. Odent M (1983) Birth under water. Lancet 24:1476-1477

3. House of Commons Health Committee (1992) Maternity service: second report (Winterton report). Her Majesty's Stationary Office, London

4. Dudenhausen JW, Eldering G, Grauel EL, Groneck P, Huch R, Husslein P, Moll W, Pohlandt F, Schneider KTM, Zimmerman R (2004) Stellungsnahme zur Wassergeburt. Leitlinien, Empfehlungen, Stellungsnahmen der deutschen Gesellschaft für Gynäkologie und Geburtshilfe, September 2004

5. Royal College of Obstetricians and Gynaecologists. Births in water. Available: http://www.rcog.org.uk/medical/birth.html

6. Woodward J, Kelly SM (2004) A pilot study for a randomized controlled trial of water birth versus land birth. BJOG 111:537-545

7. Geissbuehler V, Stein S, Eberhard J (2004) Waterbirths compared with landbirths: an observational study of nine years. J Perinat Med 32:308-314

8. Bodner K, Bodner-Adler B, Wierrani F, Mayerhofer K, Fousek C, Niedermayr A, Grunberger W (2002) Effects of water birth on maternal and neonatal outcomes. Wien Klin Wochenschr 114:391-395

9. Otigbah CM, Dhanjal MK, Harmsworth G, Chard T (2000) A retrospective comparison of water births and conventional vaginal deliveries. Eur J Obstet Gynecol Reprod Biol 91:15-20

10. Clinical effectiveness support unit (2001) The use of electronic fetal monitoring. The use of cardiotocography in intrapartum fetal surveillance. Evidence-based clinical guideline number 8. RCOG Press, London

11. Schorn M, McAlister J, Blanco J (1993) Water immersion and the effect on labor. J Nurse Midwifery 38:336-342

12. Aird IA, Luckas MJ, Buckett WM, Bousfield P (1997) Effects of intrapartum hydrotherapy on labour related parameters. Aust N Z J Obstet Gynaecol 37:137-142
13. Zimmermann R, Huch A, Huch R (1993) Water birth-is it safe? J Perinat Med 21:5-11

14. Mc Candlish R, Renfrew M (1993) Immersion in water during labour and birth: the need for evaluation. Birth 20:79-85

15. Rawal J, Shah A, Stirk F, Mehtar S (1994) Water birth and infection in babies. BMJ 309:511

16. Nguyen S, Kuschel C, Teele R, Spooner C (2002) Water birth: a near drowning experience. Pediatrics 110:411-413

17. Bowden K, Kessler D, Pinette M, Wilson E (2003) Underwater birth: missing the evidence or missing the point? Pediatrics 112:972-973

18. Cluett ER, Nikoderm VC, McCandlish RE, Burns EE (2004) Immersion in water in pregnancy, labour and birth. Cochrane Database Syst Rev, issue 1, art. no. CD000111.pub2. DOI 10.1002/14651858.CD000111.pub2

19. Pinette MG, Wax J, Wilson E (2004) The risks of water birth. Am J Obstet Gynecol 190:1211-1215

20. Schröcksnadel H, Kunczicky V, Meier J, Brezinka C, Oberaigner W (2003) Gebären im Wasser-Erfahrungen einer Universitätsklinik und eines Bezirkskrankenhauses in Österreich. Gyn Geburtsh Rundsch 43:7-11

21. Woodward J, Kelly SM (2004) A pilot study for a randomized controlled trial of water birth versus land birth. BJOG 111:537-545

22. Geissbühler V, Eberhard J (2003) Erfahrunge mit der Unterwassergeburt. Eine prospektive longitudinale Studie über 9 Jahre mit fast 4000 Wassergeburten. Gyn Geburtsh Rundsch 43:12-18

23. Ohlsson G, Buchhave P, Leandersson U, Nordstrom L, Rydhstrom H, Sjolin I (2001) Warm tub bathing during labour: maternal and neonatal effects. Acta Obstet Gynecol Scand 80:311-314

24. Rush J, Burlock S, Lambert K, Loosley Millman M, Hutchison B, Enkin M (1996) The effects of whirlpool baths in labor: a randomized controlled trial. Birth 23:136-143

25. Eckert K, Turnbull D, MacLennan A (2001) Immersion in water in the first stage of labour: a randomized controlled trial. Birth 28:84-93

26. Cammu H, Clasen K, Van Wetteren L, Derde M (1994) To bathe or not to bathe during first stage of labor. Acta Obstet Gynecol Scand 73:468-472

27. Cammu H, Clasen K, Van Wetteren L (1992) Is having a warm bath during labour useful? J Perinat Med 20:104

28. Geissbuehler V, Eberhard J (2000) Waterbirths: a comparative study. A prospective study on more than 2000 waterbirths. Fetal Diagn Ther 15:291-300

29. Barry CN (1995) Water births: could saline in the pool reduce the potential hazards? BMJ 310:1602

30. Rawal J, Shah A, Stirk A, Mehtar S (1994) Water birth and infection in babies. BMJ 309:511 